\title{
A Case Serie Report of Laparoscopic Vaginoplasty Surgery Using Modified Vecchietti Method in Vaginal Agenesis
}

\section{A R T I C L E I N F O}

\section{Article Type}

Case Report

\section{Authors}

Saremi A.* $M D$,

Bahrami H. ${ }^{1} M D$,

Hamideh Khoo T. ${ }^{1} M D$

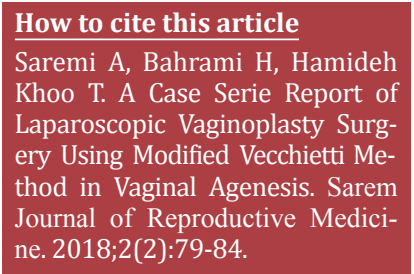

*"Sarem Fertility \& Infertility Research Center (SAFIR)" and "Sarem Cell Research Center (SCRC)”, Sarem Women's Hospital, Tehran, Iran ${ }^{1}$ Sarem Fertility \& Infertility Research Center (SAFIR), Sarem Women's Hospital, Tehran, Iran

\section{Correspondence}

Address: Sarem Women's Hospital, Basij Square, Phase 3, Ekbatan Town, Tehran, Iran. Postal Code: 1396956111

Phone: +98 (21) 44670888

Fax: +98 (21) 44670432

saremiat@yahoo.com

\section{Article History}

Received: January 11, 2017

Accepted: May 25, 2017

ePublished: June 15, 2018

\section{A B S T R A C T}

Patients Information Laparoscopic Vaginoplasty with Modified Vecchietti Technique is a new method in the treatment of vaginal agenesis. In this method, a combination of dilatation and graftless surgery is used. This technique was first developed in 1992 for the first time in the world, and it was used in Sarem Hospital in 2009 for the first time in Iran. After primary examinations and the definitive diagnosis of Mayer-Rokitansky and Kuster-Hauser syndrome, 9 patients with vaginal agenesis were operated by Laparoscopic Vaginoplasty, using Modified Mecchietti Technique between 2009 and 2014; their surgical outcomes and their subsequent consequences including sexual satisfaction were followed up and studied. Only 2 out of 9 patients had complaints about their vaginal length because of lack of regular intercourse. The average time for surgery was 2 hours and 8 minutes and the mean vaginal length was $6.5 \mathrm{~cm}$. According to the last patients' follow up, the minimum increased vaginal length was $3 \mathrm{~cm}$ and maximum vaginal length was $10 \mathrm{~cm}$. Also, the average hospitalization time was 7.3 days.

Conclusion All in all, compared with other vaginoplasty methods, the mentioned technique has fewer side effects and it is more effective. Because of lack of transplantation, there was no side effect of transplantation.

Keywords Vagina; Vaginoplasty; Laparoscopic Surgery; Modified Vecchietti Technique 


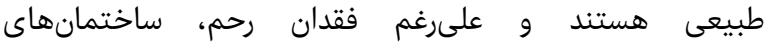
تكاملنيافتناى از رحم هم ممكن است در سايزها و اشكال مختلف ديده شوند[1]. در جنين شرايطى از آنجا كه رحم وجود ندارد، قاعدكى رخ نمى نمدهدي،

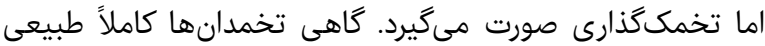

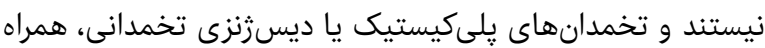

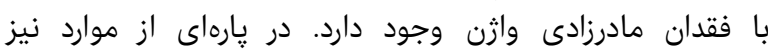

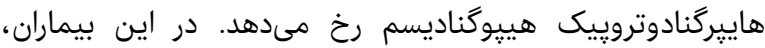

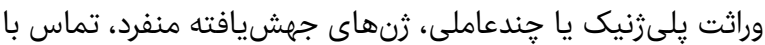

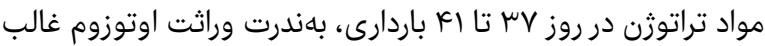

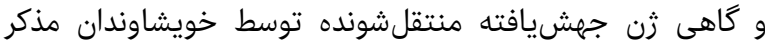

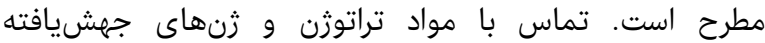
محتملترين علل هستند [1].]

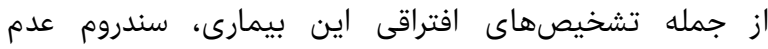

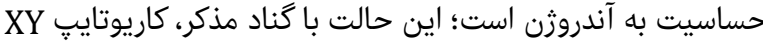

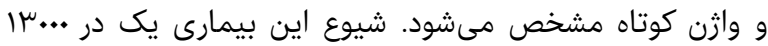

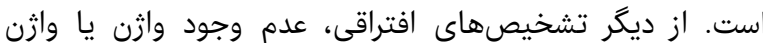

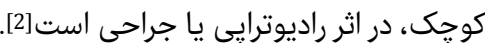

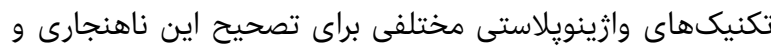

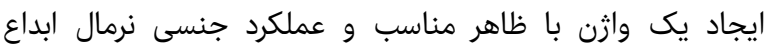

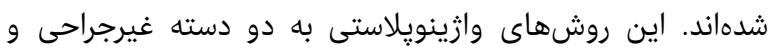

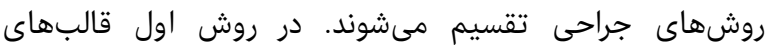

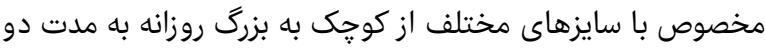

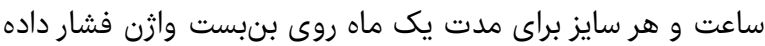

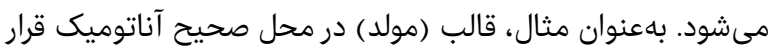

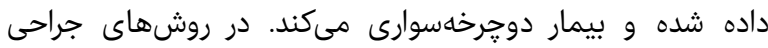

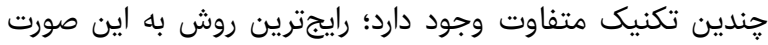

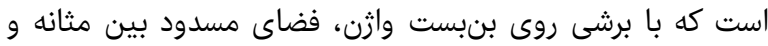

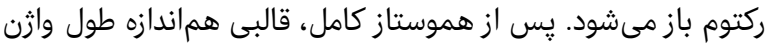

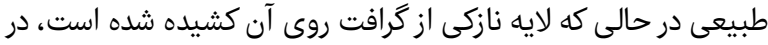

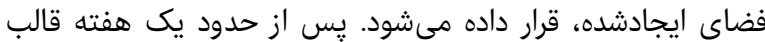

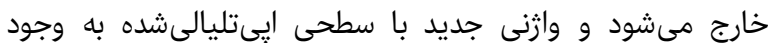

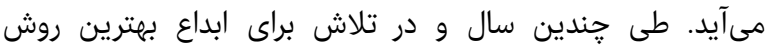

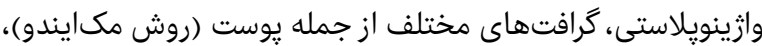

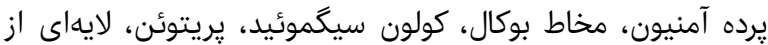

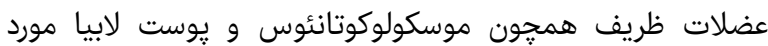

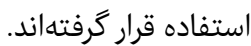

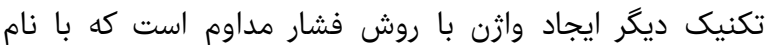

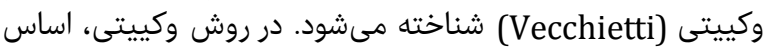

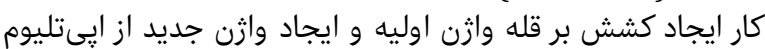

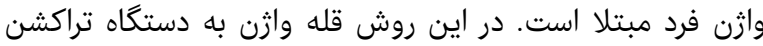

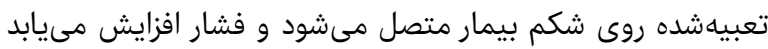

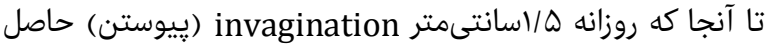

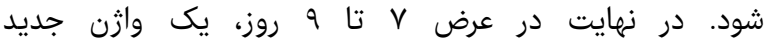

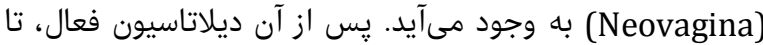

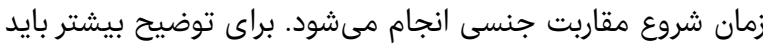

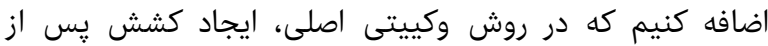

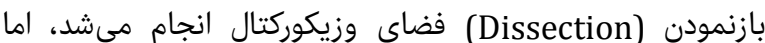

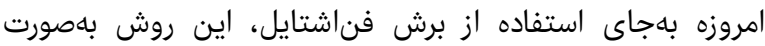

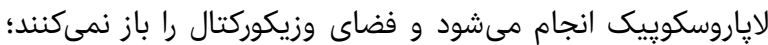

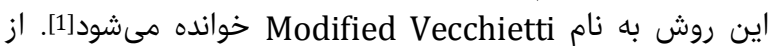

ارايه و تشريح شيوه نوين جراحى وازينويلاستى

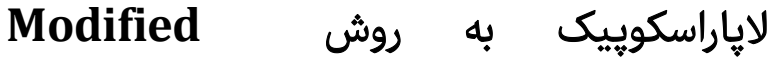
S د 9 بيمار مبتلا به آرنزى واثرن Vecchietti

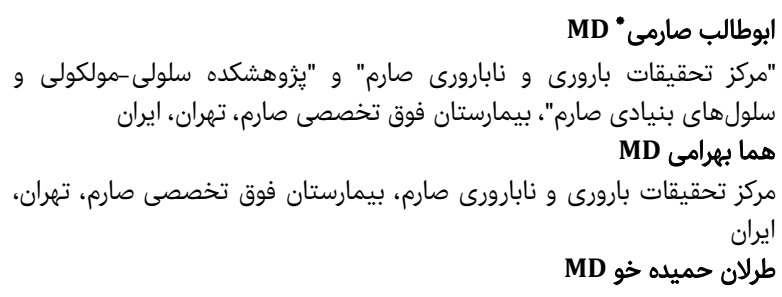
مركز تحقيقات بارورى و نابارورى صارم، بيمارستان فوق تخصصى صارم، تهران،

קֶ: مشيده

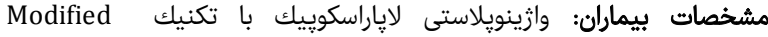

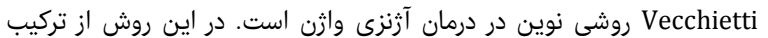

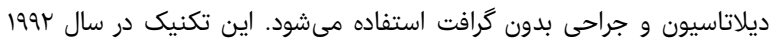

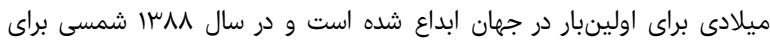
اولينبار در ايران در بيمارستان فوق تخصصى إنى صارم مورد استفاده قرار گرفته

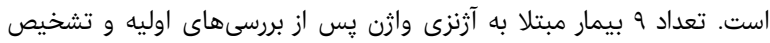

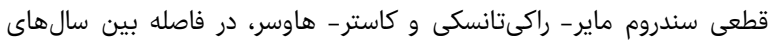

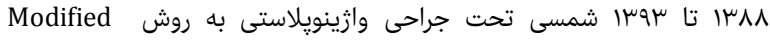

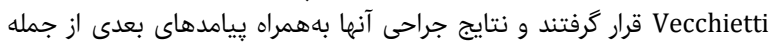

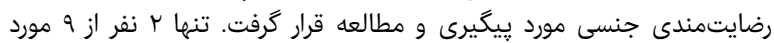

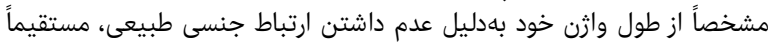

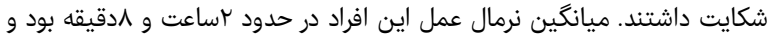

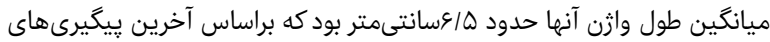

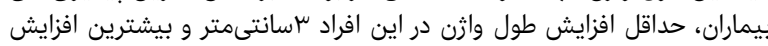

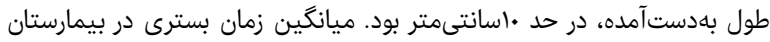

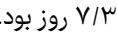
نتيجهگيرى: در مجموع تكنيك فوق در مقايسه با ساير روشهاى واثرينويلاستى،

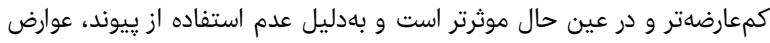

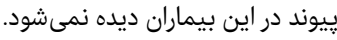

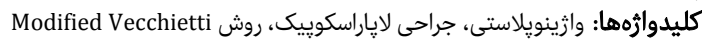

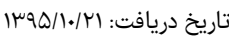

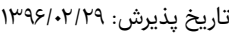

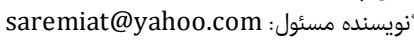

مقدمه

در اختلال فرآيند تكامل مجارى مولرين، هنكام منشاكيرى از اين إين

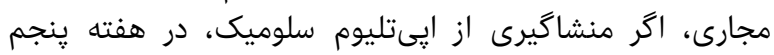

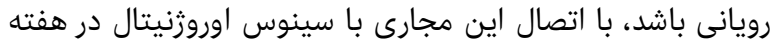

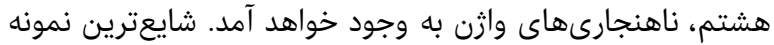

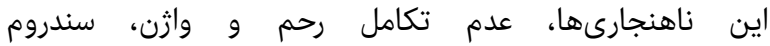

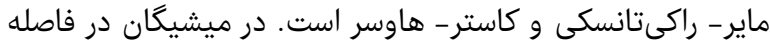

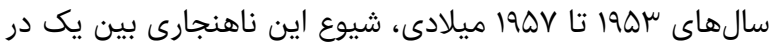

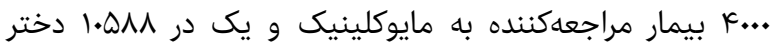

متولدشده، گزارش شده است [1].

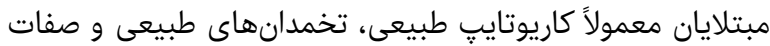

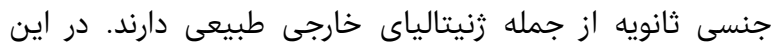

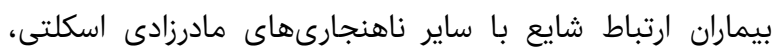
اورولوزيك و بهويزه كليوى وجود دارد. لولهها و تخمدانهانها مادرائ معمولاً 


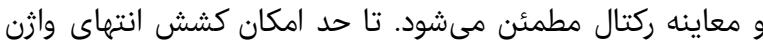

بهورت سرى - شكمى (كرانيوونترال) اعمال مى شود (شكل سـان).

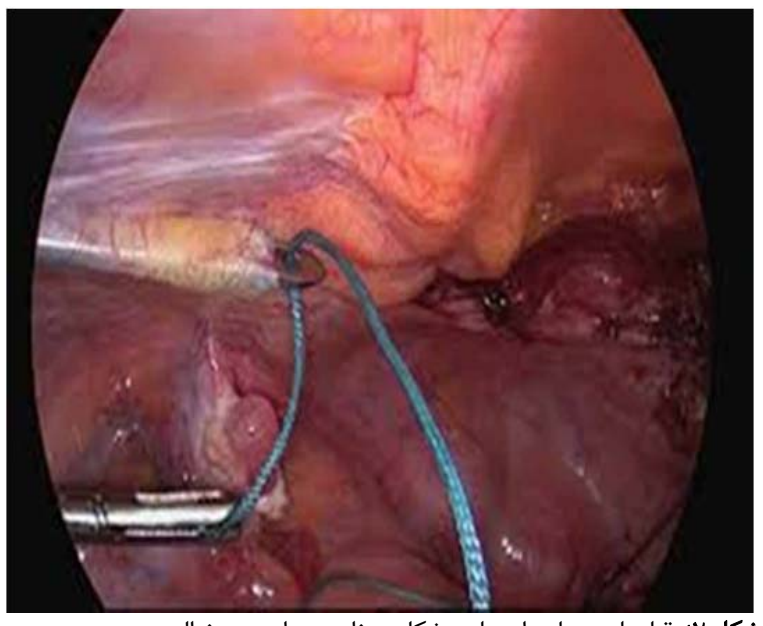

شكل r قرار دادن ميلههاى داسى شكل در ناحيه سابِيريتونيال

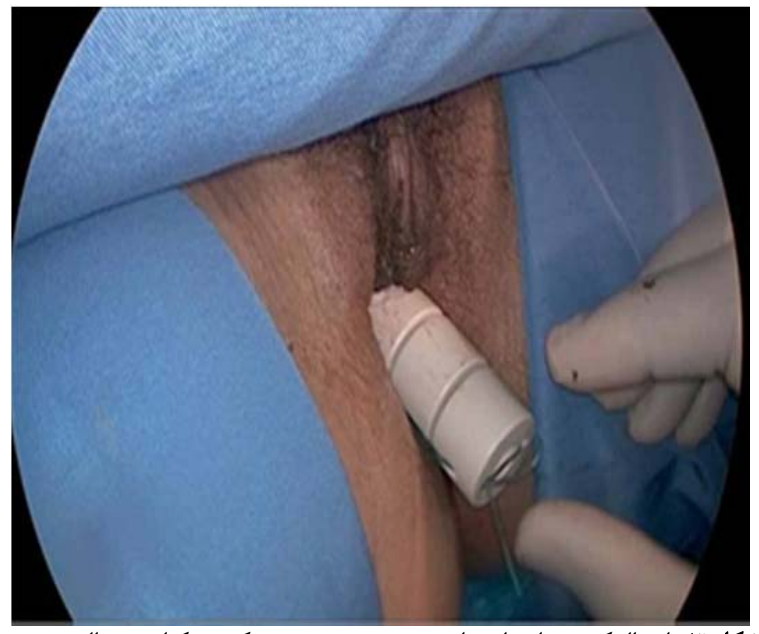

شكل س) اعمال كشش انتهاى واثن به صورت سرى - شكمى (كرانيوونترال)

وسيله كشش (Traction Device) به سطح جدار شكم متصل

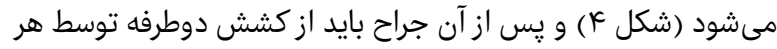

دو نخ مطمئن شود.

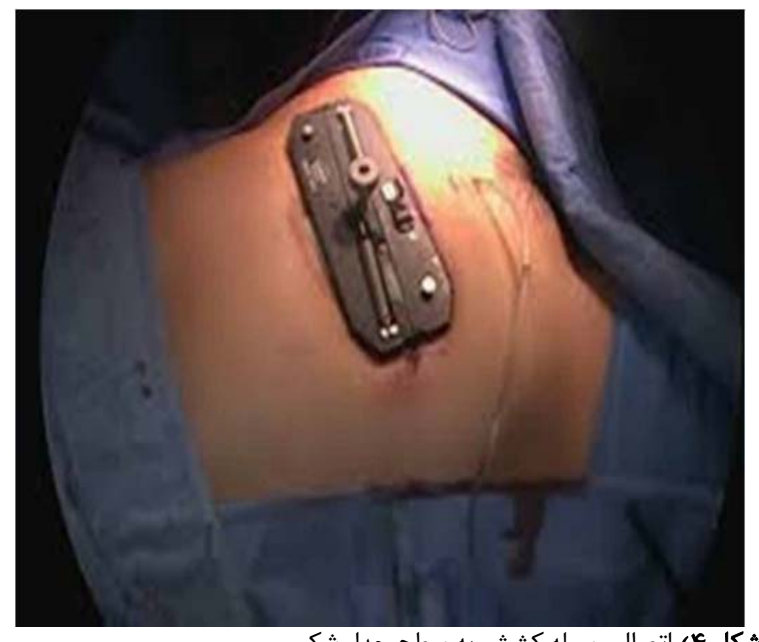

شكل F) اتصال وسيله كشش به سطح جدار شكم

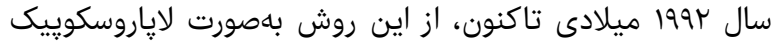

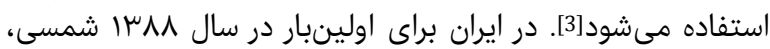

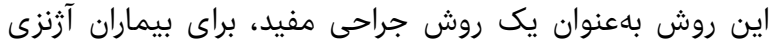

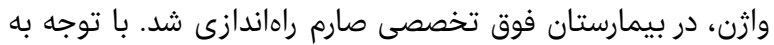

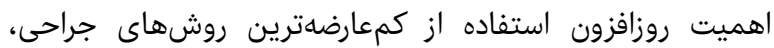

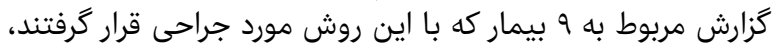
ارايه شده است.

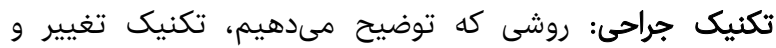

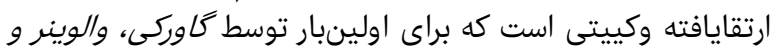

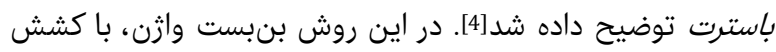

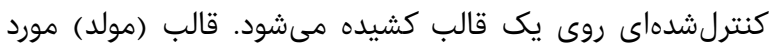

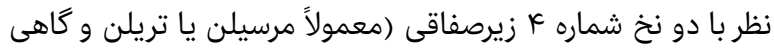

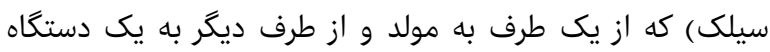

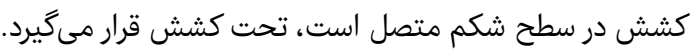

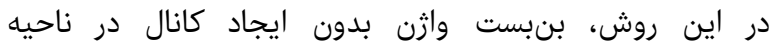

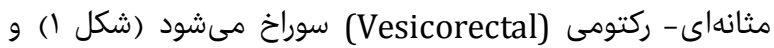
فرآيند سوراخشدن همزمان بهوسيله لإياراسكويى و سيستوسكويى

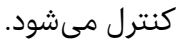

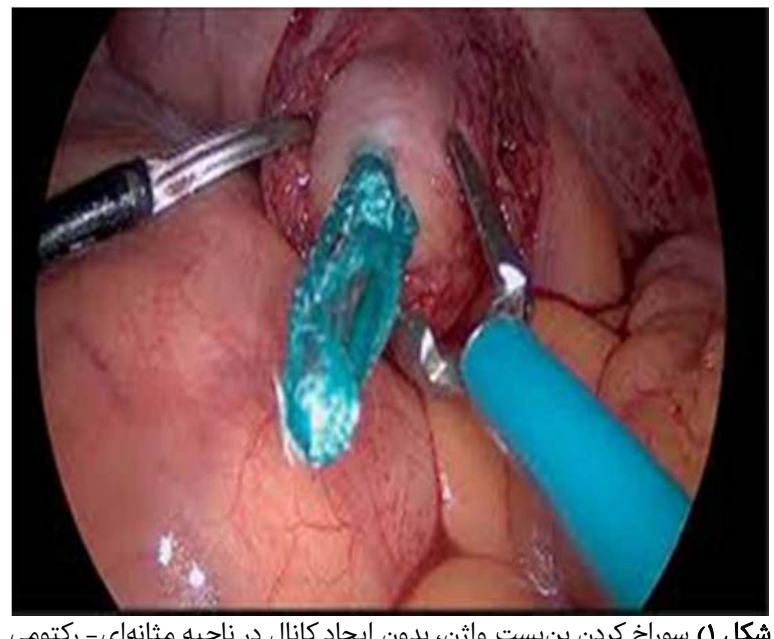

شكل () سوراخ كردن بنبست واثن، بدون ايجاد كانال در ناحيه مثانهاى- ركتومى

(Vesicorectal)

بنبست وازن، با فشار انگشت در جهت ناف به سمت شكم هدايت

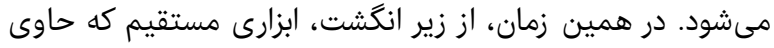

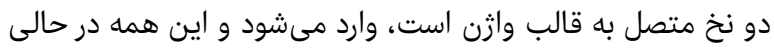

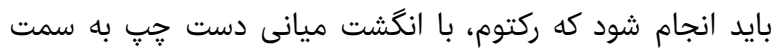

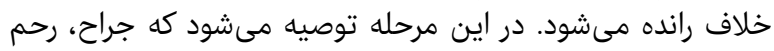

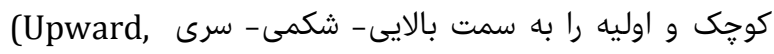
ventrally and cranially) است كه مطمئن شويم مثانه در محل ايجاد سوراخ قرار نمى زئيرد.

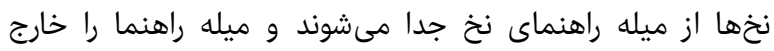

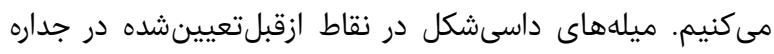
شكم، در ناحيه سابِيريتونيال قرار داده مى دشود (شكل ؟ ؟).

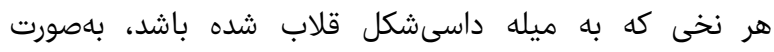

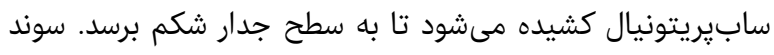

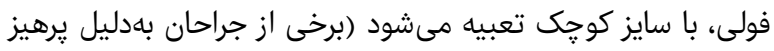

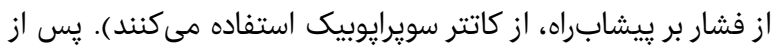

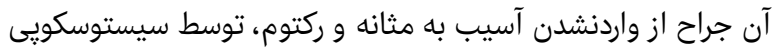


از q بيمار جراحىشده، در F مورد، هيرسوتيسم و در يك مورد، هاييرآندروزنيسم وجود داشت و مشكارئل

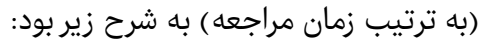

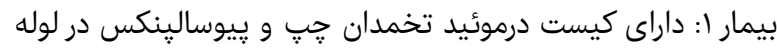

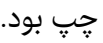

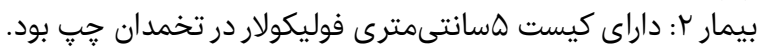

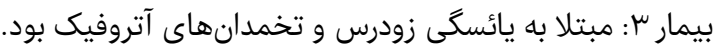

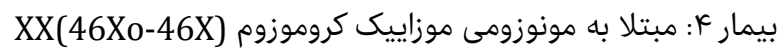

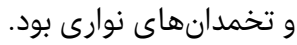
بيمار ه: داراى تخمدان توان نواري لوداى يلىكيستيك بود.

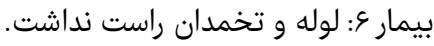

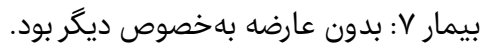

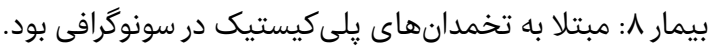

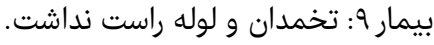

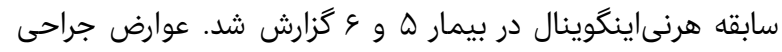

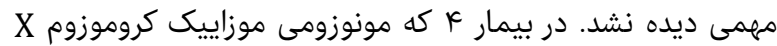

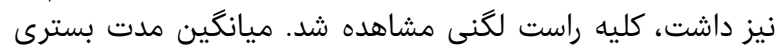

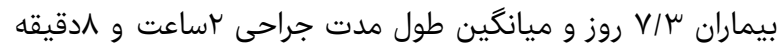

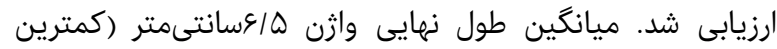

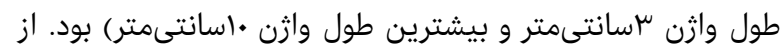

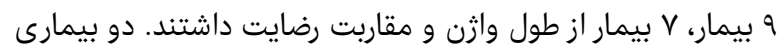

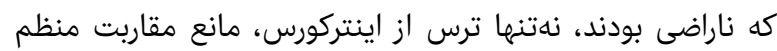

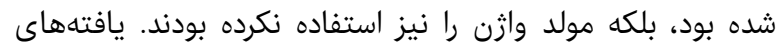
بهدست آمده در جدول إو مول خلاصه شدهاند.

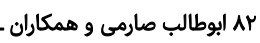

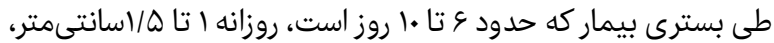

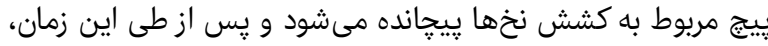

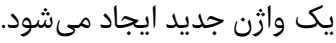

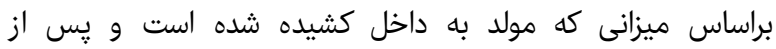

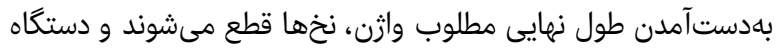

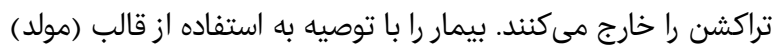

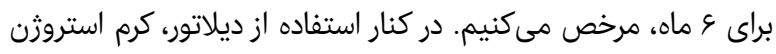

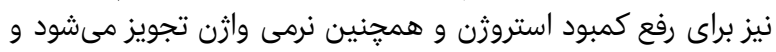

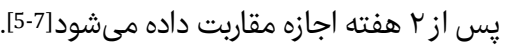

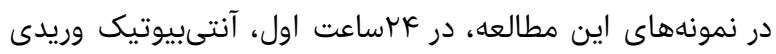

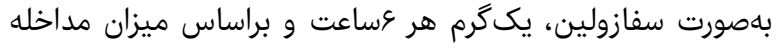

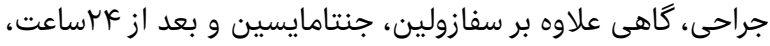

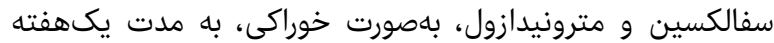
تجويز شد.

\section{بيماران و روشها}

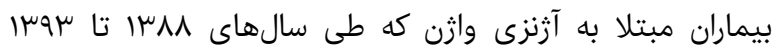

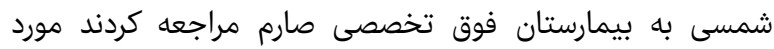

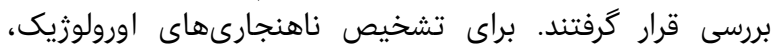

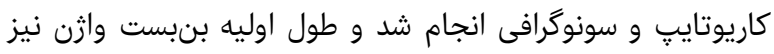

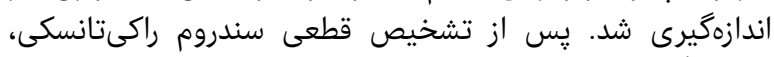

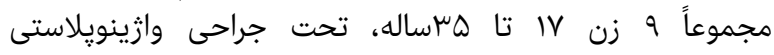

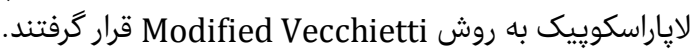

جدول ا) اطلاعات بالينى و نتايج وازينويلاستى لاياراسكوِى در 9 مراجعهكننده به بيمارستان فوق تخصصى صارم

\begin{tabular}{|c|c|c|c|c|c|c|c|c|c|}
\hline بيمارج & بيمار A & بيمار V & بيمارع & بيماره & بيمار F & بيمارس & بيمارץ & بيمارا & مواد بررسى \\
\hline r & rᄉ & re & rq & 19 & IV & $\mu \omega$ & 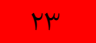 & $r q$ & سن (سال) \\
\hline$K \in X X$ & - & - & - & - & $\begin{array}{l}k \notin X X \\
k 7 X 0\end{array}$ & $F \notin X X$ & $k \in X X$ & - & كاريوتايي \\
\hline$r$ & $r / 1 Q$ & r & $r / \mu$. & r & $r / 1$. & $1 / F \Delta$ & $1 / 0$ & $\mu$ & مدت عمل جراحى \\
\hline$\checkmark$ & $\checkmark$ & $\checkmark$ & $\Delta$ & $\checkmark$ & 11 & 9 & $\Delta$ & $\wedge$ & مدت بسترى (روز) \\
\hline مرسلين & مرسلين & سيلك & مرسلين & مرسلين & مرسلين & مرسلين & سيلك- & مرسلين & نج مورد استفاده تراكشن \\
\hline$r$ & $1 / 0$ & r & 1 & $\Delta$ & r & r & $\mu$ & k & طول واثر قبل از عمل (سانتىمتر) \\
\hline 1. & 9 & v & 1. & 9 & F & द & k & 1. & طول واثر بعد ازعمل (سانتىمتر) \\
\hline 1. & 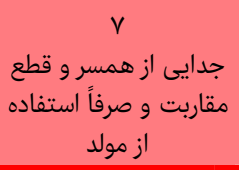 & $\varepsilon$ & 1. & $\Lambda / \Delta$ & عدم استفاده از مولد & $\varepsilon$ & $\Delta$ & $\mu$ & 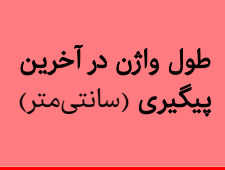 \\
\hline راضى بسيار & $\begin{array}{l}\text { (ارضاى وازينار ناراضى) } \\
\text { وازيال) }\end{array}$ & راضى & بسيار راضى & بسيار راضى & بسيارناراضى & راضى & راضى & بسيار ناراضى & رضايتمندى همسر از \\
\hline
\end{tabular}


جدول r) اطلاعات بالينى و نتايج وازينويلاستى لاياراسكويى در 9 مراجعهكننده به بيمارستان فوق تخصصى صارم

\begin{tabular}{|c|c|c|c|}
\hline سابقه بيمارى & يافتههاى حين عمل & عوارض عمل & مواد بررسى \\
\hline- & 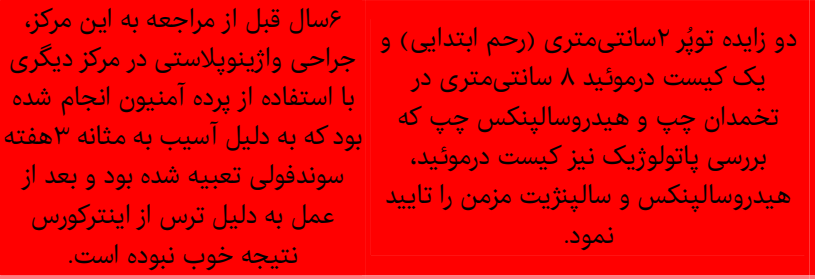 & 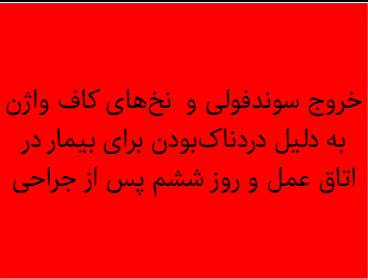 & \\
\hline هيرسوتيسم آكنه، مقاومت & كيست ديده نشد، لولهها و تخمدانها نرمال درى تخمدان جي & 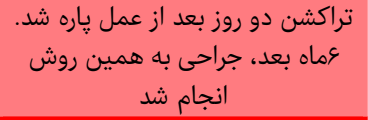 & \\
\hline 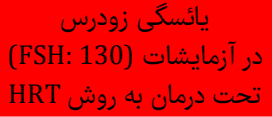 & رحم ندارد. تخمدان ها و لوله ها آتروفيك & - & , \\
\hline هيرسوتيسم مونوزومى موزاييك & 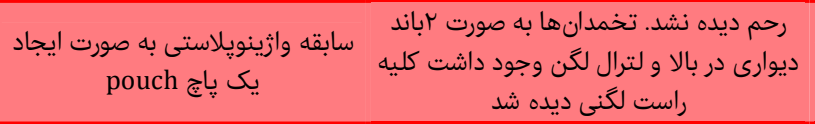 & هماجورى گذرا & 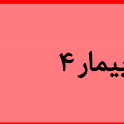 \\
\hline 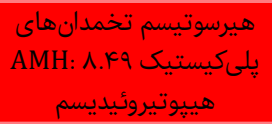 & 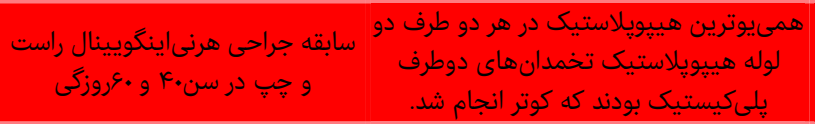 & قطع جريان ادرار به دليل فشار يروتز & ه \\
\hline- & 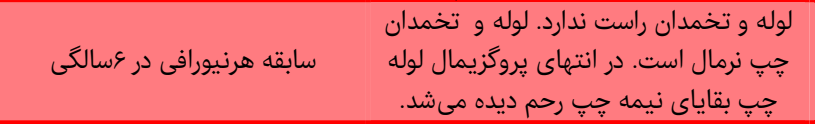 & هماجورى گذرا & 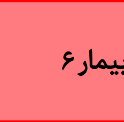 \\
\hline- & 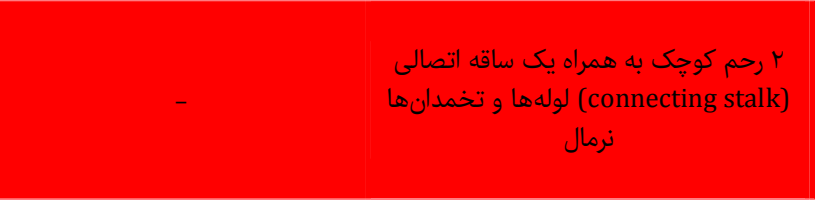 & 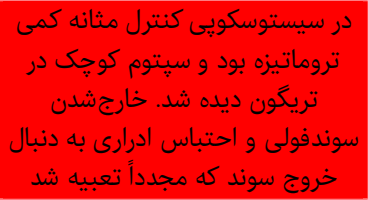 & v \\
\hline 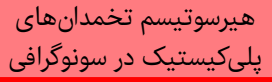 & 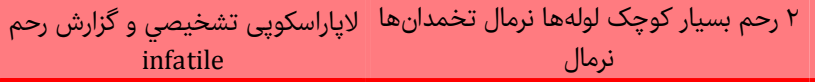 & - & A \\
\hline هاييرآندروزنيسم در آزمايشات & 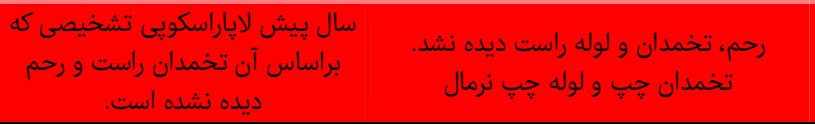 & - & \\
\hline
\end{tabular}

بازنمودن فضا (با بيمار) و با استفاده از ابزارهاى قديمى صورت

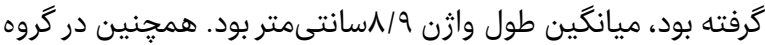

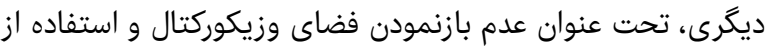

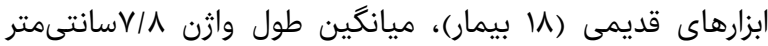

كزارش شد [3].

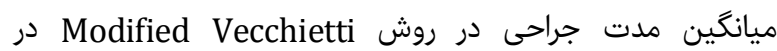

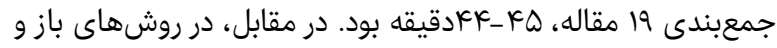

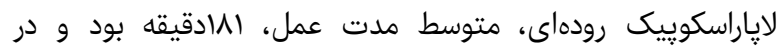

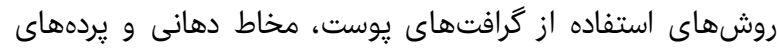

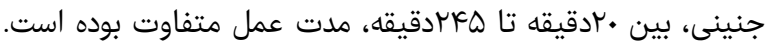

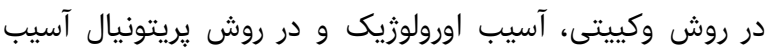

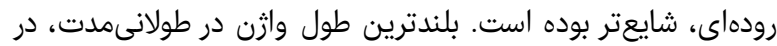

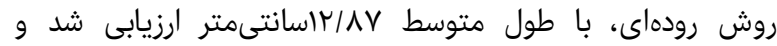

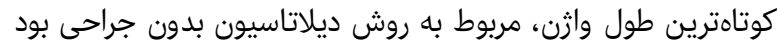

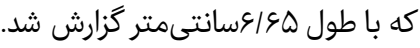

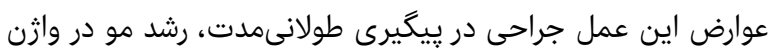

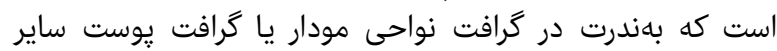

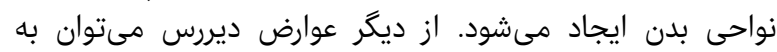

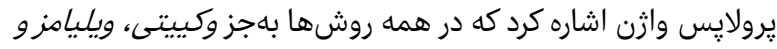

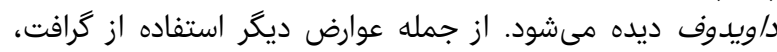

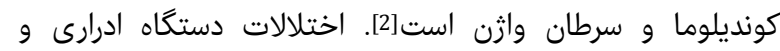

در اين مطالعه ميانگين طول واثن بلهدستآمده با استفاده از

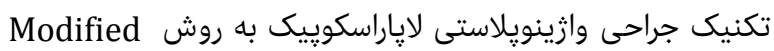
Vecchietti

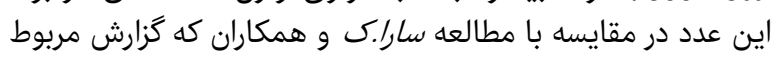

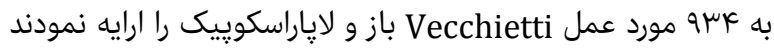

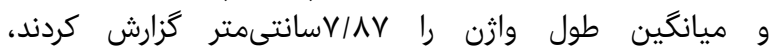

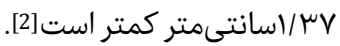

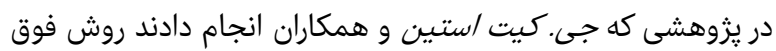

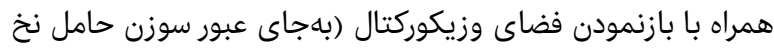

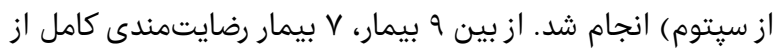

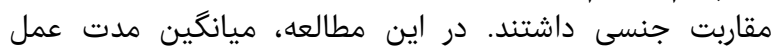

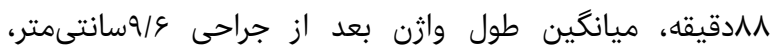

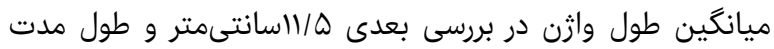

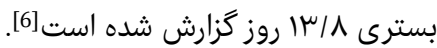

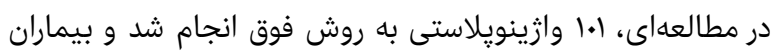

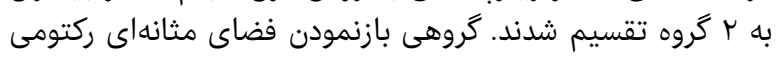

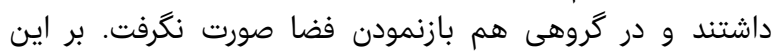

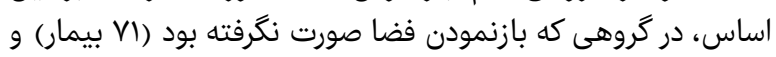

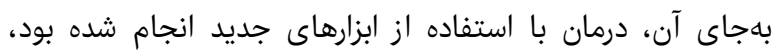

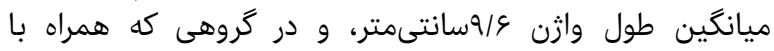


تخصصى صارم و همجنين از جناب آقاى ايرج شصتى كمال تشكر

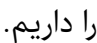

تاييديه اخلاقى: موردى از سوى نويسندكان ذكر نشده است.

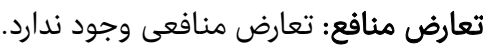

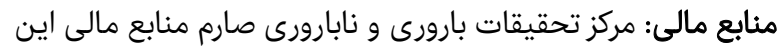

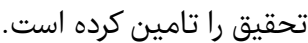

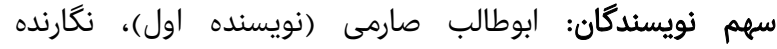

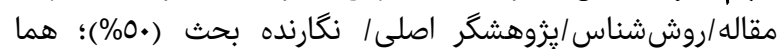

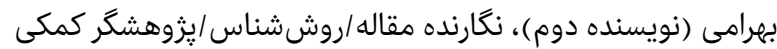

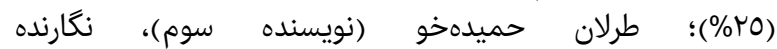

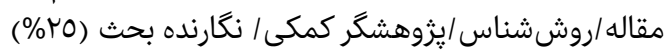

\section{منابع}

1- Jones HW, Rock JA. Te Linde's operative gynecology. Philadelphia: Lippincott Williams \& Wilkins; 2015.

2- McQuillan SK, Grover SR. Dilation and surgical management in vaginal agenesis: a systematic review. Int Urogynecol J. 2014;25(3):299-311

3- Brucker SY, Gegusch M, Zubke W, Rall K, Gauwerky JF, Wallwiener D. Neovagina creation in vaginal agenesis: Development of a new laparoscopic Vecchietti-based procedure and optimized instruments in a prospective comparative interventional study in 101 patients. Fertil Steril. 2008 Nov;90(5):1940-52.

4- Gauwerky J, Wallwiener D, Bastert G. An endoscopically assisted technique for construction of a neovagina. Arch Gynecol Obstet. 1992;252(2):59-63.

5- Viola M, Van der Merwe J, Siebert T, Kruger T. Neovagina creation-laparoscopic Vecchietti-based approach with the new kit. South African J Obstet Gynaecol. 2013;19(1).

6- Keckstein J, Kandolf O, Rauter G, Hudelist G. Long-term outcome after laparoscopic creation of a neovagina in patients with Mayer-Rokitansky-Küster-Hauser syndrome by a modified Vecchietti procedure. Gynecol Surg. 2008;5(1):21-5.

7- Nezhat C, Nezhat F, Nezhat C. Nezhat's Video-Assisted and Robotic-Assisted Laparoscopy and Hysteroscopy with DVD. England: Cambridge University Press; 2013.
ابوطالب صارمى و همكاران

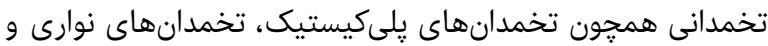

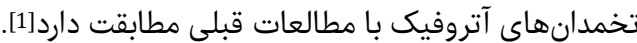

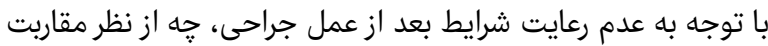

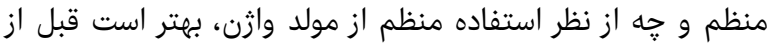

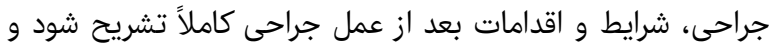

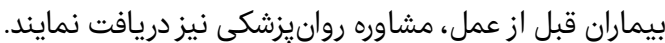

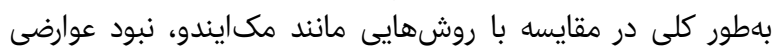

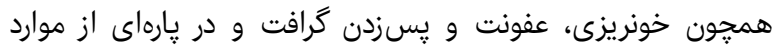

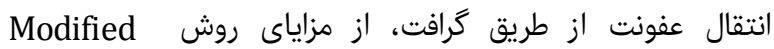
Vecchietti

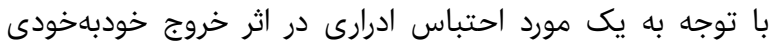

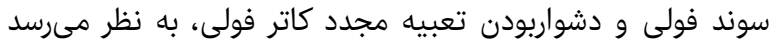

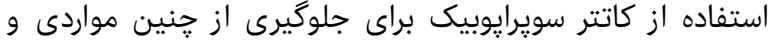

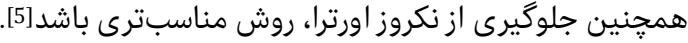

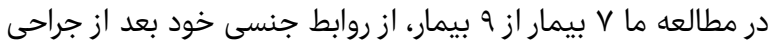

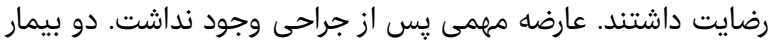

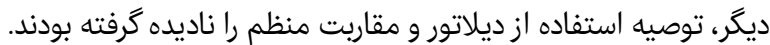

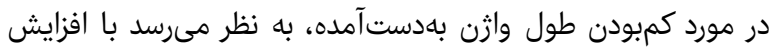

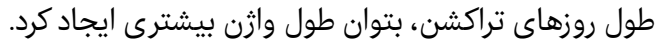

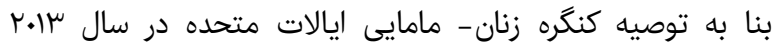

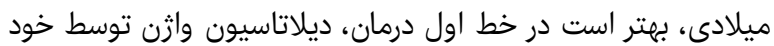

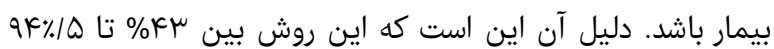

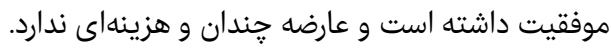

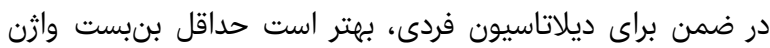

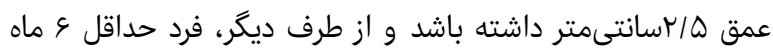

$$
\text { بهورت روزانه اين كار را انجام دهد [2]. }
$$

$$
\text { نتيجه }
$$

در مجموع مىتوان گفت تكنيك Modified Vecchietti نسبت بـانه ساير روشهاى وازينويلاستى عارضه كمترى دارد و در عين حال

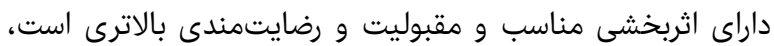

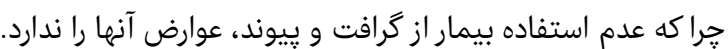

تشكر و قدردانى: از همكاران گرامى اتاق عمل بيمارستان فوق 